\title{
Cañón de ozono para la destrucción de la carga viral en ambientes públicos.
}

\author{
Gustavo E. Romero ${ }^{1,2,3}$; Martín Salibe ${ }^{1}$; Daniel Perilli ${ }^{1}$; Leandro García ${ }^{1}$ \\ ${ }^{1}$ Instituto Argentino de Radioastronomía (IAR), CONICET-CICPBA-UNLP, Buenos Aires, Argentina; \\ 2 Facultad de Ciencias Astronómicas y Geofísicas (FCAyG), Universidad Nacional de La Plata; \\ 3gustavo.esteban.romero@gmail.com
}

Resumen. Se está desarrollando un dispositivo capaz de generar grandes cantidades de ozono en forma controlada. El aparato está dotado de una batería de sensores que le permite interactuar con el medio hasta lograr que el ozono inyectado alcance la concentración adecuada en un tiempo determinado para garantizar la destrucción de la carga viral en un ambiente cerrado. El dispositivo fue desarrollado por el área de Transferencia de Tecnología del Instituto Argentino de Radioastronomía (IAR) con el objetivo de proveer una herramienta de desinfección de espacios de uso común para el período de retorno a la actividad laboral y educacional presencial al fin de la pandemia de COVID-19. La desinfección de aulas, oficinas, vehículos de transporte, comedores, laboratorios, y otros espacios entre dos ocupaciones sucesivas de usuarios tiende a minimizar las posibilidades de rebrotes y contagios incontrolados. El equipo está diseñado para destruir bacterias, esporas, hongos y ser muy eficaz en la inactivación de otras especies de microorganismos ya que su modo principal es la oxidación directa de la pared celular. Es capaz, logrando las concentraciones adecuadas de ozono, de neutralizar todo tipo de virus, tanto en aire como en superficies. En este documento se describe el dispositivo, la tecnología usada, su efectividad, y la forma más eficiente de su aplicación.

Palabras clave: ozono; desinfección; carga viral; ingeniería de control

Recibido: 24/09/2020 Aceptado: 30/09/2020

DOI: https://doi.org/10.24215/26838559e022 


\section{Ozone generator for the destruction of viral load in public environments.}

Abstract. A device capable of generating large amounts of ozone in a controlled manner is being developed. The device is equipped with a battery of sensors that allows it to interact with the environment until the ozone injected reaches the appropriate concentration to guarantee the destruction of the viral load in a closed environment. It was developed by the Technology Transfer area of the Argentine Institute of Radio Astronomy (IAR) with the aim of providing a disinfection tool for use in close spaces of frequent human occupation during the period of return to face-toface work and educational activity at the end of the COVID-19 pandemic. The disinfection of classrooms, offices, transport vehicles, dining rooms, laboratories, and other closed spaces between two successive occupations of users tends to minimize the possibilities of uncontrolled outbreaks and infections. The equipment is designed to destroy bacteria, spores, fungi and to be very effective in the inactivation of other species of microorganisms since its main mode is the direct oxidation of the cell wall. It is capable, by achieving the appropriate concentrations of ozone, of neutralizing all types of viruses, both in air and on surfaces. This document describes the device, the technology used, its effectiveness, and the most efficient way to apply it.

Keywords: ozone; disinfection; viral load; control engineering.

\section{Contexto: Instituto Argentino de Radioastronomía y transferencia de} tecnología

El Instituto Argentino de Radioastronomía (IAR) es una unidad de investigación básica y de desarrollo de tecnología dependiente del Consejo Nacional de Investigaciones Científicas y Técnicas (CONICET), la Comisión de Investigaciones Científicas de la Provincia de Buenos Aires (CICPBA) y la Universidad Nacional de la Plata (UNLP). Fue creado en 1962 para promover las investigaciones y tecnologías en el área de la radioastronomía y ciencias afines. Se encuentra localizado en el 
Parque Pereyra Iraola y cuenta con laboratorios, oficinas y dos radiotelescopios de $30 \mathrm{~m}$ de diámetro que se utilizan para investigar emisiones de radio de objetos astronómicos como ser púlsares, cuásares, galaxias y gas interestelar.

El instituto cuenta con una estructura consistente en un sector científico y un sector tecnológico. Este último a su vez incluye dos grandes áreas: el observatorio y la transferencia de tecnología (TT). A disposición de estas áreas hay departamentos de electrónica, sistemas, electromecánica y mantenimiento.

La forma en que se ha generado la TT en el instituto es paradigmática del círculo virtuoso de realimentación positiva entre ciencia básica y desarrollo de tecnología. Los objetivos científicos fijan requerimientos tecnológicos para que los equipos e instrumentos puedan obtener cierta clase de datos. Esto hace que el sector tecnológico del instituto desarrolle nuevas tecnologías, las que a su vez dan lugar a desarrollos tecnológicos específicos y a conocimiento tecnológico nuevo que queda a disposición del sector de transferencia para su aplicación a otras áreas y usos. Comenzando en el área de los receptores radiastronómicos y la ingeniería de señales, las capacidades tecnológicas del instituto rápidamente se expandieron hacia la transferencia de tecnología al sector aeroespacial y de comunicaciones. El IAR ha contribuido con tecnología a misiones tan variadas como el satélite SAC-D (cámara NIRST, el radiómetro de microondas MWR y computadora de vuelo), los satélites SAOCOM A y B (diseño de las antenas SAR), los vectores VEX 1 y 5 del lanzador Tronador, y actualmente contribuye a la misión Sabia-MAR con la cámara 
TIR y trabajos de software para la computadora de vuelo. Además, ha brindado tecnología y colaborado con INVAP, CONAE, CNEA, y empresas privadas. El sector de vinculación dentro del área de TT identifica problemas a los que el IAR puede brindar soluciones tecnológicas y establece los canales para su implementación. Esto se ilustra en la Figura 1.

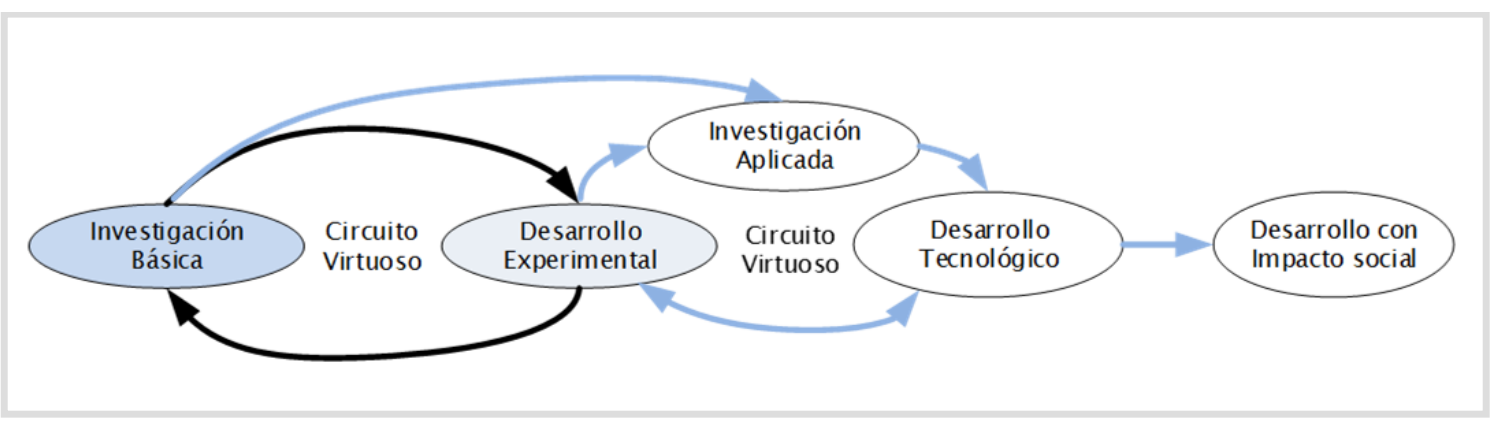

Figura 1. Esquema con el funcionamiento del proceso de transferencia tecnología en el IAR.

Figure 1. Scheme with the operation of the technology transfer process in the IAR.

Esta metodología ha sido aplicada a la excepcional situación presentada por la pandemia de COVID-19, que ha puesto en jaque la economía y la capacidad sanitaria a escala planetaria.

Tan pronto se declaró el estado de pandemia en la Argentina, el sector de TT realizó un relevamiento de las necesidades del sistema de salud a nivel provincial y nacional y analizó las posibles respuestas tecnológicas a problemas concretos que se podrían brindar con la tecnología disponible en el IAR y el know-how acumulado a lo largo de la historia de la institución. El resultado fueron dos propuestas concretas: un 
ventilador mecánico no invasivo (VMNI) para asistir a pacientes con deficiencia respiratoria moderada, pensado para la fase crítica de la pandemia, y un dispositivo de desinfección que sea efectivo y de bajo costo para la etapa de recuperación económica y reapertura de la actividad social, pensado para destruir la carga viral en ambientes cerrados entre dos ocupaciones sucesivas de los mismos. Esto último podría ser un elemento clave para evitar rebrotes y posibilitar una reapertura controlada y relativamente segura de la actividad económica. Es este desarrollo de un sistema de desinfección basado en ozono el que se presenta en lo que resta de este trabajo.

\section{Requerimientos}

Los requerimientos básicos que debería cumplir el dispositivo para desinfección de ambientes cerrados son los siguientes:

- Sistema eficiente para destruir el $99.9 \%$ de la carga viral en tiempos no mayores de 20 minutos en ambientes de hasta $100 \mathrm{~m}^{2}$.

- La desinfección producida debe ser homogénea dentro de todo el volumen de aplicación en forma independiente de los contenidos y forma física del ambiente.

- Sistema que no presente peligros para la salud humana o animal. No debe dejar residuo tóxico alguno.

- Alimentación por corriente alterna $220 \mathrm{~V}$. 
- Equipo transportable en forma manual.

- Adaptabilidad al uso dentro de vehículos y transportes públicos, incluyendo vagones de ferrocarril.

- Robustez y facilidad de construcción.

- Sistemas de control que permitan que el equipo opere con mínima intervención humana.

- Capacidad de control remota.

- Costo bajo.

\section{Uso del ozono para destrucción de carga viral en aire y superficies}

Con la especificación de los requerimientos, el equipo de TT investigó el potencial de desinfección de diferentes tecnologías: químicos, luz UV y ozono. Se vio que el ozono ha sido usado para desinfección de agua en forma eficaz durante décadas. Esta molécula está formada por tres átomos de oxígeno $\left(\mathrm{O}_{3}\right)$. Se encuentra presente en forma natural en la alta atmósfera, donde absorbe la radiación UV proveniente del sol. Su poder desinfectante se basa en que oxida la membrana lipídica que recubre a microorganismos y virus. Una vez rota esta membrana, los microorganismos mueren y, en el caso de los virus, al penetrar oxígeno y acoplarse con el ARN de los mismos, se desactiva su capacidad reproductora (e.g. Shinriki et al. 1988). La inactivación de virus por medio de ozono ha sido extensamente probada en el laboratorio, sobre todo en agua. En el caso de virus en suspensión en 
aire o sobre superficies, hay diferentes estudios con distintas clases de virus incluidos sustitutos de coronavirus (e.g. Hudson et al., 2007, 2009; Dubuis et al. 2020). La inactivación de la carga viral depende marcadamente de la concentración de ozono, las condiciones ambientales (en particular humedad), el tipo de superficie, y el lapso de exposición a la concentración de $\mathrm{O}_{3}$.

En la Figura 2 puede verse la cinética de la inactivación de diferentes virus frente a una concentración de ozono de 10 partes por millón (ppm). En el eje de las ordenadas se grafica la fracción activa de virus mientras que en el de las abscisas se indica el tiempo de exposición al ozono (Hudson et al. 2009).
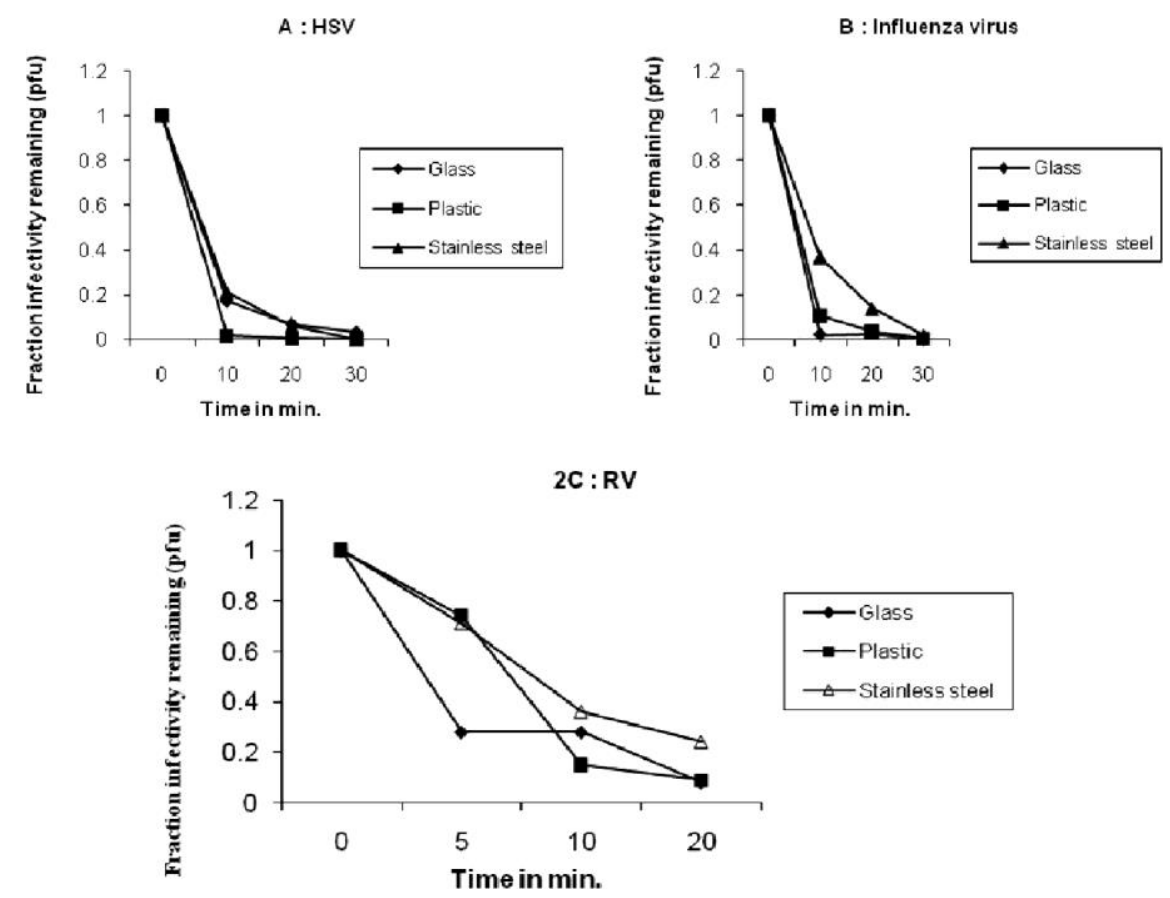

Figura 2. Disminución de la carga viral en función del tiempo para diferentes virus y superficies frente a una concentración de ozono en aire de 10 ppm. HVS: virus del herpes, RV: rhinovirus. Reproducido de Hudson et al. (2009). 
Figure 2 (previous page). Decrease in viral load as a function of time for different viruses and surfaces compared to an ozone concentration in air of $10 \mathrm{ppm}$. HVS: herpes virus, RV: rhinovirus. Reproduced from Hudson et al. (2009).

La resistencia de los virus al $\mathrm{O}_{3}$ depende de la humedad. A mayor humedad es más rápida la caída de la fracción activa de virus, en todas las superficies. Con concentraciones de 10 ppm en unos 30 minutos esencialmente toda la carga viral ha sido destruida. A mayores concentraciones los lapsos se acortan. Resultados similares se obtuvieron para la carga viral en aire (Dubuis et al 2020). Al presente no se conoce ningún virus resistente al ozono en las concentraciones mencionadas (Hudson et al. 2009). Los experimentos incluyen al coronavirus murino (M-CoV), una especie de coronavirus que infecta a los ratones.

\section{Desarrollo del producto}

Basados en las consideraciones brevemente mencionadas en la sección anterior, el área de TT del IAR generó una serie de requerimientos tecnológicos que debe satisfacer un equipo de desinfección por ozono para operar en forma eficaz en la destrucción de la carga viral. La elección del ozono como agente desinfectante se basó en su probada efectividad, la posibilidad de su producción utilizando como insumo el aire ambiente, el hecho de que al ser el ozono en condiciones normales un gas puede llenar completamente los espacios a desinfectar logrando una 
desinfección completa, y el hecho de que decae rápidamente una vez que ha cumplido su función.

Específicamente, los dos requerimientos tecnológicos esenciales que se fijaron fueron:

- El equipo debe ser capaz de generar una alta concentración de ozono en tiempos cortos.

- El equipo debe contar con un sistema de control inteligente que regule el funcionamiento en función de las indicaciones de sensores que provean información sobre la concentración de $\mathrm{O}_{3}$ en el ambiente, la temperatura y la humedad.

El primero de estos requisitos implica utilizar una tecnología más eficiente para producir ozono que el efecto corona, que es la usualmente aplicada en los ozonizadores comerciales ${ }^{1}$ que se emplean en sanitización y desodorización. Luego de una investigación detallada de las posibilidades tecnológicas más relevantes, se decidió basar la producción de ozono en la inyección de aire tomado del ambiente sobre una cámara de plasma frío. Esta está formada por una serie de placas que producen un plasma superficial por descarga de barrera dieléctrica (DBD) estimulada por un voltaje/frecuencia regulable por el procesador del sistema. En la Figura 3 se muestra un esquema de una placa de DBD, similar a las que serán

\footnotetext{
${ }^{1}$ Estos equipos están orientados a la destrucción parcial de la carga bacteriana y son inefectivos para actuar sobre virus.
} 
usadas en el reactor de plasma (Portugal et al 2017). El ozono es creado cuando el oxígeno ambiente es inyectado sobre el plasma, en un proceso de dos pasos. Primero el oxígeno molecular es disociado por los electrones libres del plasma y luego un átomo de oxígeno liberado por el proceso anterior se acopla a una molécula de $\mathrm{O}_{2}$ resultando en $\mathrm{O}_{3}$. Las reacciones relevantes son: $e+\mathrm{O}_{2} \rightarrow \mathrm{O}+\mathrm{O}+e$, $\mathrm{O}+\mathrm{O}_{2}+\mathrm{M} \rightarrow \mathrm{O} 3+\mathrm{M}$. Aquí, e representa a un electrón libre y $\mathrm{M}$ una molécula de la superficie del dieléctrico (si la reacción ocurre en aire $\mathrm{M}$ puede $\operatorname{ser} \mathrm{O}_{2} \circ \mathrm{N}_{2}$ ). Esto es ilustrado en la Figura4.

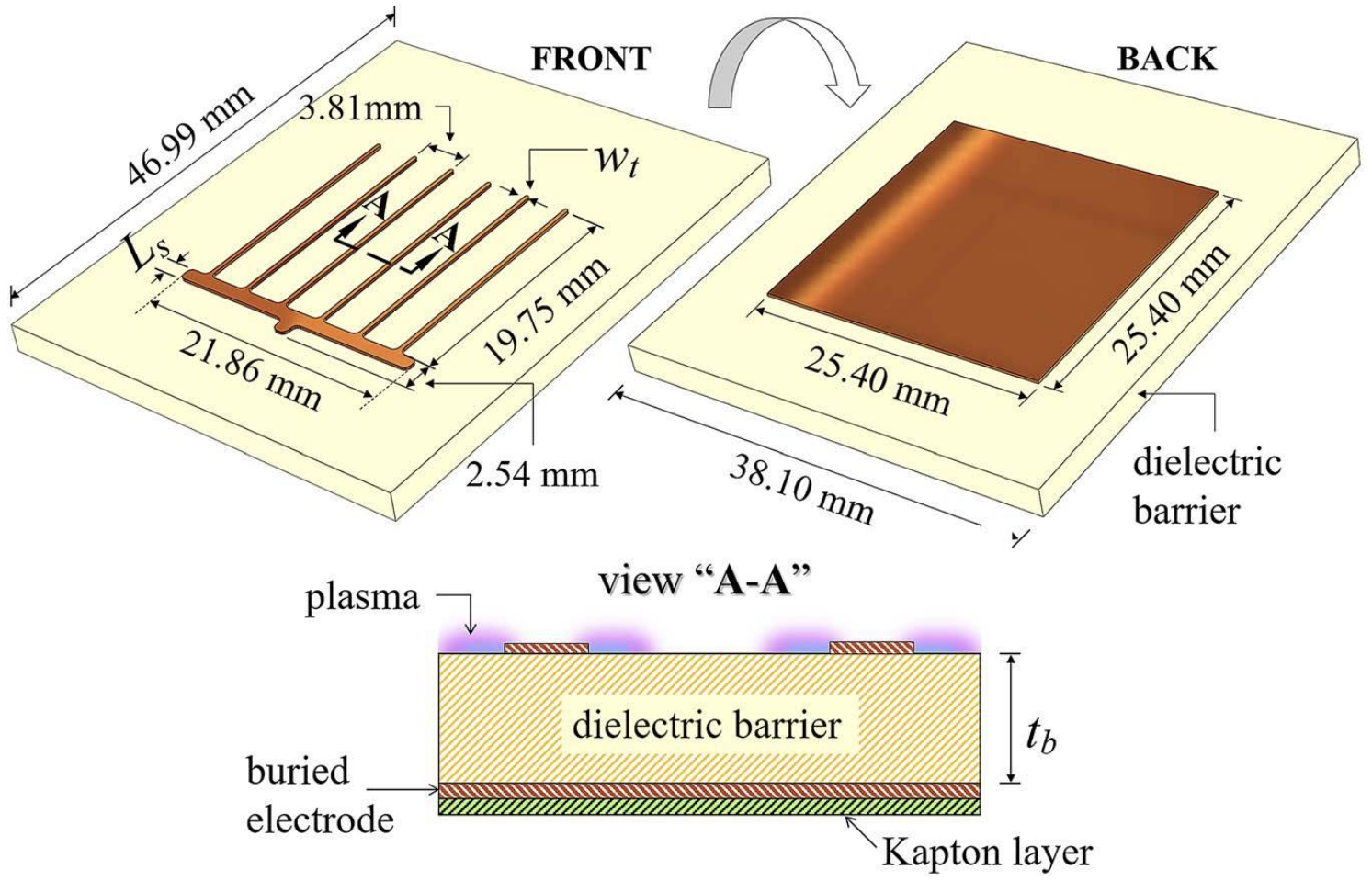

Figura 3. Configuración de una placa de descarga de barrera dieléctrica similar a las que son utilizadas para crear una cámara de plasma. De Portugal et al. (2017).

Figure 3. Configuration of a dielectric barrier discharge plate similar to those used to create a plasma chamber. From Portugal et al. (2017). 


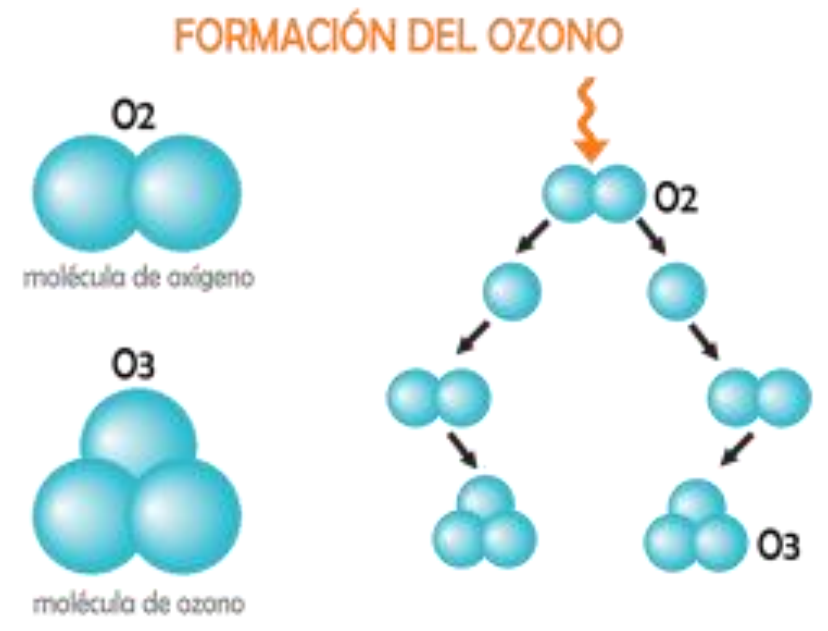

Figura 4. Proceso en dos pasos para formar ozono en una cámara de plasma sobre la base de inyección de oxígeno molecular ambiente. A la izquierda se ilustran moléculas de oxígeno y de ozono.

Figure 4. Two-step process to form ozone in a plasma chamber based on ambient molecular oxygen injection. Oxygen and ozone molecules are illustrated on the left.

Al contar la cámara de plasma con numerosas placas DBD es posible lograr grandes cantidades de ozono y concentraciones mucho mayores que con simple efecto corona. Sobre la efectividad del método ver, por ejemplo, Ono \& Oda (2007), Pekárek (2013) y Zhang et al. (2016).

La Figura 5, muestra cómo se acumula el $\mathrm{O}_{3}$ en la salida de la cámara. Hay una primera fase de crecimiento lineal rápido del ozono, que luego desacelera debido al aumento de la destrucción del mismo por interacción con oxígeno atómico. Cuando el reactor se apaga, la concentración decae exponencialmente con el tiempo. Los experimentos muestran una clara dependencia con el tipo de material dieléctrico 
utilizado y con la frecuencia aplicada. Los mejores resultados ocurren con materiales cerámicos y frecuencias altas (14 kHz y 8.5k Vpp). En menos de $200 \mathrm{~s}$, se acumulan unas $600 \mathrm{ppm}$ de $\mathrm{O}_{3}$ por placa.
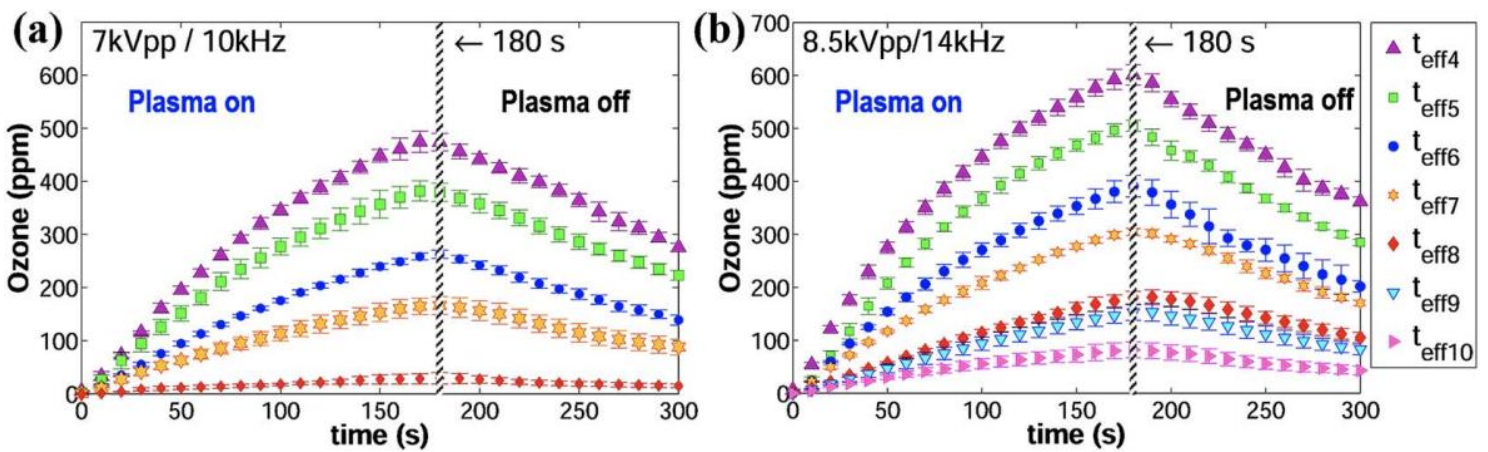

Figura 5. Incremento de la concentración de ozono en la salida de la cámara de plasma para diferentes materiales dialécticos en la placa DBD y para dos diferentes voltajes de pico a pico y dos diferentes frecuencias aplicadas (10 kHz a la izquierda y $14 \mathrm{kHz}$ a la derecha). Los mejores resultados se obtienen con materiales cerámicos. De Portugal et al. (2017).

Figure 5. Increase in the ozone concentration at the outlet of the plasma chamber for different dialectical materials on the DBD plate and for two different peak-to-peak voltages and two different applied frequencies (10 $\mathrm{kHz}$ to the left and $14 \mathrm{kHz}$ to the right). The best results are obtained with ceramic materials. From Portugal et al. (2017).

El segundo de los requerimientos tecnológicos, el control inteligente de las funciones del equipo, está a cargo de un micro-controlador Atmega328p (basado en el entorno Arduino). Se propone este micro-controlador dado que es robusto, versátil, fácil de programar y la disponibilidad en el mercado local del mismo es 
amplia. Esto permitirá acortar los tiempos de integración con los demás dispositivos de Arduino, reduciendo los tiempos de desarrollo y los de puesta en marcha del sistema. Plantearlo en este entorno no solo servirá para el prototipo inicial, sino también para la cadena de ensamble y los tiempos de reparación una vez que el equipo salga al mercado.

El micro-controlador será el cerebro del equipo, manejará las interfaces con los periféricos (teclado, display y puertos), las alarmas, temporizadores, el forzador de aire y el sistema de alta tensión que alimenta a las placas generadoras de ozono. También el micro-controlador digitalizará los sensores para realizar la correcta supervisión de los parámetros normales de utilización. Mediante la lectura de sensores externos, realizará los cálculos relevantes a la operación y enviará por sus puertos información sobre los niveles detectados de $\mathrm{O}_{3}$, temperatura y humedad para que el usuario pueda imprimir fácilmente un reporte de desinfección, acorde a su necesidad.

Monitorizando los parámetros mediante un control proporcional, integrador y derivativo, el micro-controlador será capaz de controlar en forma segura la generación de ozono en la cámara de plasma. La programación del software estará organizada por una máquina de tiempos que sincronizará el firmware y las aplicaciones, de modo que permitirá la perfecta armonía entre ambos, potenciando la capacidad del equipo para atender a todos sus periféricos sin problema. 


\section{Características y prestaciones}

El diagrama general del equipo se presenta en la Figura 6.

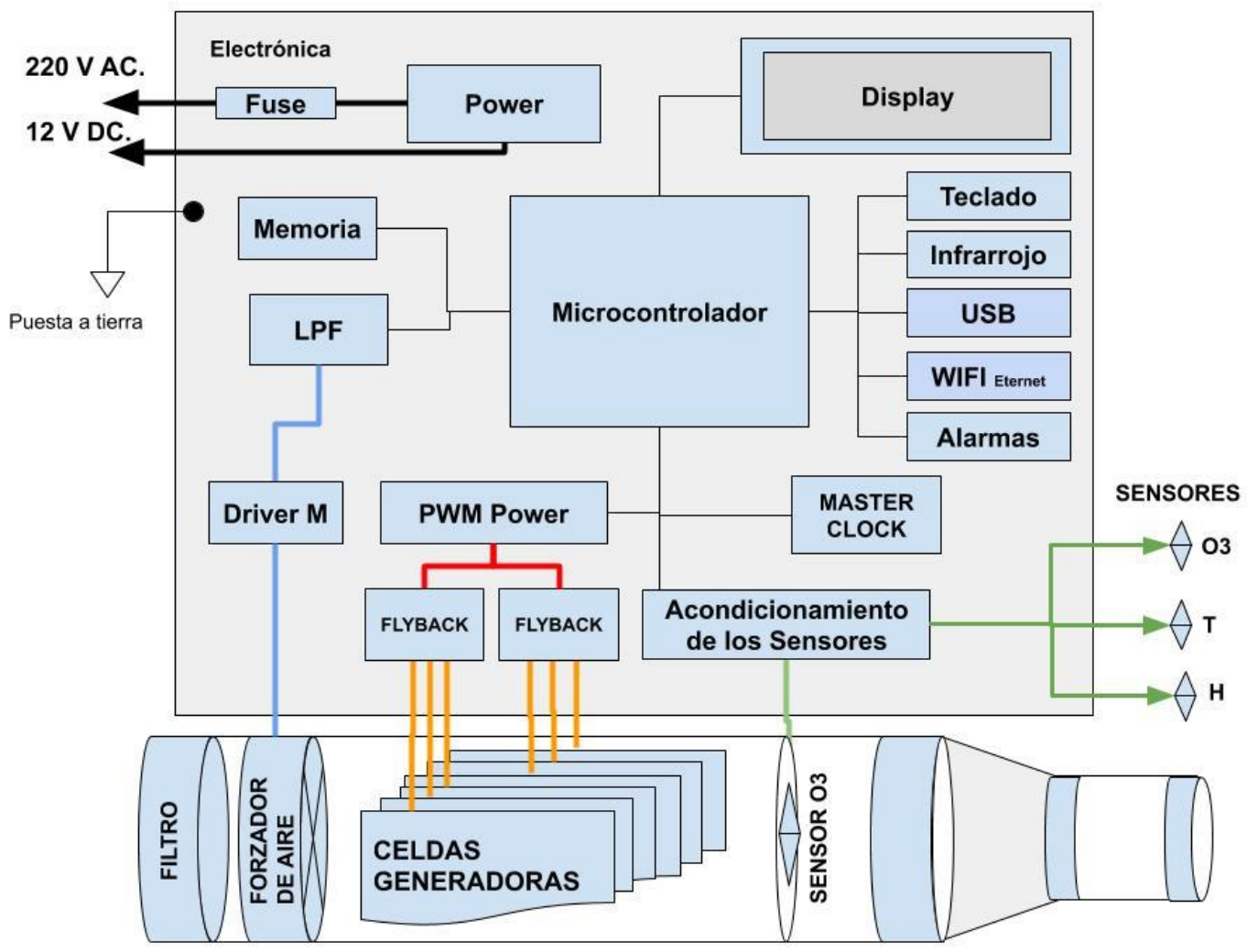

Figura 6. Diagrama general del cañón de ozono desarrollado por el IAR.

Figure 6. General diagram of the ozone cannon developed by the IAR.

Las principales componentes son:

- Micro-controlador que recibe inputs de los sensores externos e internos, y controla todas las funciones del equipo de acuerdo a un software específico.

- Los sensores externos que informan temperatura, humedad y concentración de ozono. Hay sensores locales y sensores remotos que permiten controlar el estado de la cámara de plasma y del recinto a desinfectar. 
Innovación y Desarrollo Tecnológico y Social (2020) 2 (2): 204-224- Número especial COVID-19

- Cámara de generación de ozono formada por celdas de DBD, con una capacidad para producir unos $5 \mathrm{~g}$ de ozono por hora por celda (el número total de celdas dependerá del modelo, típicamente para un equipo medio, se usarán unas 6 celdas o placas).

- Un forzador de aire, controlado por el micro, que inyectará el oxígeno tomándolo del ambiente.

- Un reloj para temporizar y sincronizar las tareas.

- Una serie de interfaces que incluyen pantalla LCD, alarmas, entrada USB para almacenar datos y cargar software, wifi, teclado, etc.

- Alimentación 220 V AC.

Una visualización del equipo es mostrada en la Figura 7.

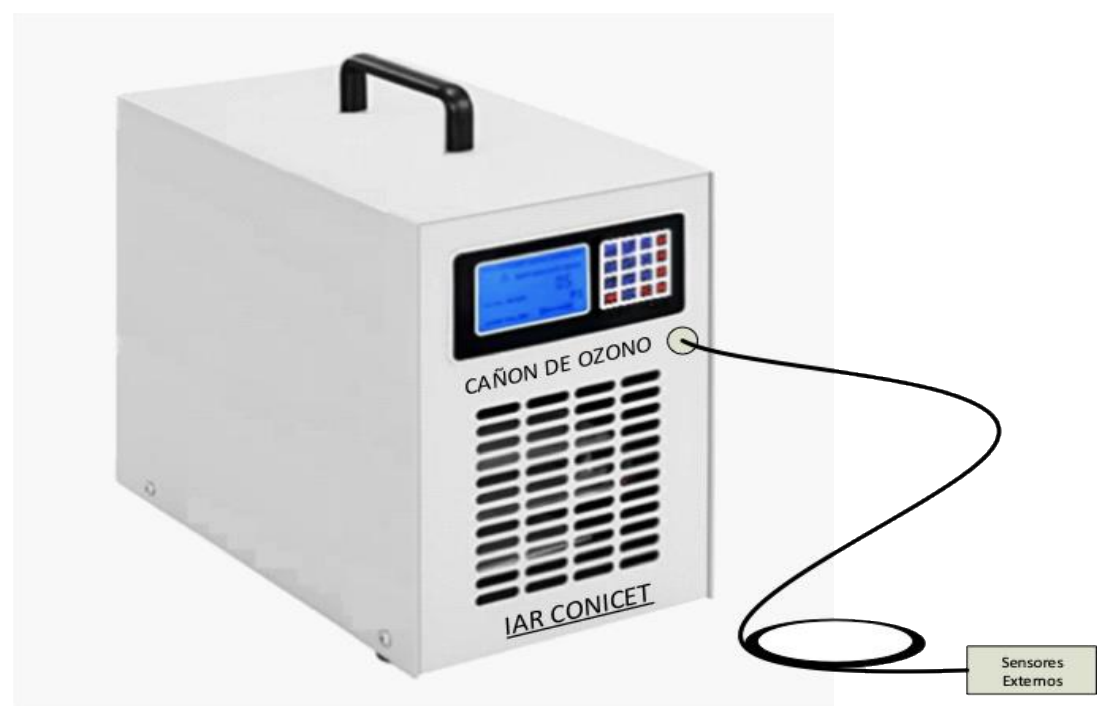

Figura 7. Aspecto externo del cañón de ozono desarrollado por el IAR. El modelo final muy probablemente se conectará con los sensores en forma inalámbrica.

Figure 7. External appearance of the ozone cannon developed by the IAR. The final model will most likely connect to the sensors wirelessly. 
El equipo final permitirá inactivar en forma completa la carga viral en todo tipo de ambientes cerrados por medio de una gran concentración de ozono (> 20 ppm) generada en un lapso corto (del orden de 10 minutos) creando lo que se denomina un "shock" de ozono. La concentración necesaria de $\mathrm{O}_{3}$ en el aire para que la carga viral se neutralice (así como la de gérmenes y bacterias, cuyas membranas externas son igualmente afectadas por el gas) depende de variables como la temperatura y la humedad, por lo que cambia de una aplicación a otra y debe determinarse in situ mediante los sensores que dispone este equipo. El cañón luego optimiza el funcionamiento para lograr el efecto deseado en el menor tiempo posible dadas las condiciones de cada ambiente, e indica por medio de alarmas cuándo la desinfección se ha completado.

El equipo desarrollado permitirá la actividad humana en forma más segura en muy diferentes ámbitos que son imprescindibles para el funcionamiento social y económico, incluyendo vehículos de transporte, oficinas, aulas, espacios públicos, baños, gimnasios, comedores, etc. La desinfección permanente con químicos de esos espacios es extremadamente onerosa, no totalmente efectiva y puede traer consecuencias indeseadas para la salud de la población.

\section{Recomendaciones para uso eficiente}

Si bien hasta el momento, y en todo el mundo, no se han registrado casos letales por intoxicación de ozono, la OMS establece límites y medidas para la exposición 
Innovación y Desarrollo Tecnológico y Social (2020) 2 (2): 204-224- Número especial COVID-19

humana (no se recomiendan concentraciones mayores a 0.2 ppm, ver OMS 2006).

En casos de sobreexposición, se han reportados síntomas de irritación debido a la sobre oxigenación de las mucosas. Es por esta razón que el equipo debe ser aplicado en ausencia de seres humanos. El equipo se podrá activar local o remotamente, y detendrá su acción al alcanzarse el nivel de esterilización adecuado. Entonces informará que la tarea finalizó y entregará un reporte (puede programarse para que sea vía web o por email). Dado que el gas de ozono difunde, alcanza todo el volumen y todas las superficies del recinto. En esto el ozono se diferencia de la luz UV, que debe alcanzar en forma directa las superficies a desinfectar. Es claro que las concentraciones adecuadas para la desinfección efectiva sólo se lograrán si el recinto está cerrado, de forma que el gas pueda acumularse antes de decaer el ozono por interacción con el medio.

La aplicación del cañón de ozono se recomienda entre dos ocupaciones sucesivas de un mismo espacio, vehículo, etc. Esto permite asegurar que no habrá contagios de un grupo humano a otro, aunque no dentro del mismo grupo si se diera el caso de que uno de los miembros del grupo estuviere infectado. Por eso, a fin de evitar al máximo la posibilidad de contagios, se sugiere complementar la utilización del cañón con medidas como la toma de temperatura de todas las personas que ingresen al recinto, a fin de detectar potenciales enfermos, y el uso de alfombras esterilizantes con productos químicos en la entrada de los recintos, a fin de que no se ingrese el virus desde el exterior luego de la esterilización. 
El método de esterilización por ozono se basa en la oxidación, por lo que la exposición reiterada a altas concentraciones de ozono de equipamiento oxidable debería evitarse a fin de no dañar maquinaria delicada. En esos casos el ozono puede reemplazarse por esterilización UV.

Por otro lado, la exposición de alimentos, muebles, papeles, camillas, vajilla, etc. es perfectamente segura. El ozono decae rápidamente en contacto con el aire y la radiación solar, por lo que desaparece naturalmente luego del proceso de esterilización de un ambiente.

\section{Conclusiones y proyección}

Se ha diseñado y está en la fase final de desarrollo un dispositivo capaz de esterilizar una gran variedad de ambientes cerrados, incluyendo vehículos y transportes, por medio del uso controlado de ozono como agente destructor de la carga viral. El equipo usa una tecnología basada en una cámara de plasma frío formada por placas de DBD a las que se excita por medio de una frecuencia controlable. La potencia se regula con un procesador que además recibe la información de una batería de sensores tanto internos como externos. Esto permite asegurar que se logran las concentraciones y exposiciones necesarias para que los ambientes queden libres de su carga viral. Como efecto secundario, se destruye también la carga de gérmenes y bacterias, disminuyendo la posibilidad de propagación de otras enfermedades además del COVID-19. 
La principal diferencia entre el producto desarrollado y los llamados "ozonizadores" que pueden encontrarse en el mercado es que la tecnología usada permite asegurar la eficacia de la esterilización al 1) generar la cantidad necesaria de ozono, y 2) controlar el proceso en forma inteligente con realimentación de información desde el entorno.

Es de esperar que la planificación en higiene y seguridad sanitaria incorpore este tipo de equipamientos a fin de minimizar la posibilidad de rebrotes durante el período post-pandemia. De esa manera se logrará facilitar la recuperación económica cuidando la salud y bienestar de la población.

En el campo científico-tecnológico, el cañón de ozono desarrollado es un ejemplo más de la versatilidad de la tecnología que resulta como retorno inmediato de la inversión en ciencia básica.

\section{Financiamiento}

Este proyecto ha sido financiado por el "PROGRAMA DE ARTICULACION Y FORTALECIMIENTO FEDERAL DE LAS CAPACIDADES EN CIENCIA Y TECNOLOGÍA COVID-19". Id: BUE 15. GER es Investigador Superior del CONICET. MS es Técnico Principal del CONICET. DP y LG son Profesionales Principales de CONICET. 


\section{Agradecimientos}

Agradecemos el apoyo del CCT La Plata, CONICET, y en especial a su Directora la

Dra. Gloria Chicote, así como a los sectores de Prensa y Vinculación de esa institución. También agradecemos a Gonzalo Márquez y María Clara Lima de la UNLP por ayuda y asesoramiento y a Ricardo de Dicco y Juan Pedrosa de ADIMRA por vinculación. Un agradecimiento especial para la Concejala Ana Herran Castagneto que impulsó la declaración del proyecto como de interés municipal.

\section{Referencias bibliográficas}

Dubuis, M-E., Dumont-Leblond, N., Laliberté, C., Veillette. M., Turgeon, N., Jean, J., et al. (2020) Ozone efficacy for the control of airborne viruses: Bacteriophage and $\begin{array}{lllll}\text { norovirus } & \text { models. } & \text { PLOS } & \text { 15(4): } & \text { 0231164. }\end{array}$

\section{https://doi.org/10.1371/journal.pone.0231164}

Hudson, J.B., Sharma, M., y Petric, M. (2007). Inactivation of Norovirus by ozone gas in conditions relevant to healthcare. Journal of Hospital Infection, 66, 40-45. https://doi.org/10.1016/j.jhin.2006.12.021

Hudson, J.B., Sharma, M., y Vimalanathan, S. (2009). Development of a practical method for using ozone gas as a virus decontaminating agent. Ozone: Science \& Engineering, 31 (3), 216-223. https://doi.org/10.1080/01919510902747969 
Innovación y Desarrollo Tecnológico y Social (2020) 2 (2): 204-224- Número especial COVID-19

OMS (2006). Material particulado, el ozono, el dióxido de nitrógeno y el dióxido de azufre.

Guías

de

Calidad

del

Aire.

https://www.who.int/publications/list/who sde phe oeh 06 02/es/

Ono, R. y Oda, T. (2007). Ozone production process in pulsed positive dielectric barrier discharge. Journal of Physics D: Applied Physics, 40, 176-182. https://ui.adsabs.harvard.edu/link gateway/2007JPhD...40..1760/doi:10.1088/0022

\section{$\underline{-3727 / 40 / 1 / 011}$}

Pékarek, S. (2013). Asymmetric properties and ozone production of surface dielectric barrier discharge with different electrode configurations. The European Physical Journal D, 67: 94, 1-7. https://doi.org/10.1140/epjd/e2013-30723-4

Portugal, S., Roy, S., y Lin, J. (2017). Functional relationship between material property, applied frequency and ozone generation for surface dielectric barrier discharges in atmospheric air. Scientific Reports 7, 6388, 1-11.

\section{https://doi.org/10.1038/s41598-017-06038-w}

Shinriki, N., Ishizaki, K., Yoshizaki, T., Miura, K., y Ueda, T. (1988). Mechanism of inactivation of tobacco mosaic virus with ozone. Water Research, 22 (7), 933-938.

Zhang, X., Lee, B.J., Im, H.G., y Cha, M.S. (2016). Ozone production with dielectric barrier discharge: Effects of power source and humidity. IEEE Transactions On Plasma Science, 44(10), 2288-2296. https://doi.org/10.1109/TPS.2016.2601246 